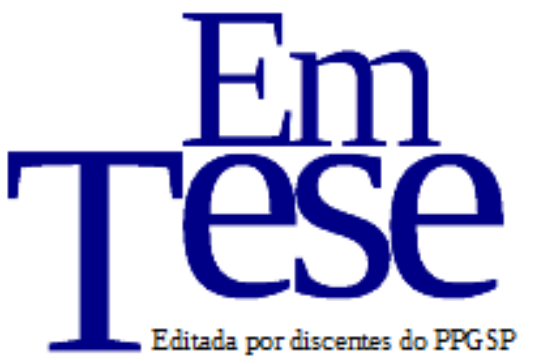

UFSC

PPG SP PROG RAMA DE

PÓS-GRADUAÇÃO EM

Sociologia

Política

v. 13, n. 1 , jan./jun., 2016

\title{
As mulheres dirigentes do partido dos trabalhadores: perfil e desafios à representação substantiva
}

\section{Tassia Rabelo de Pinho ${ }^{1}$}

\section{Introdução}

Nas últimas décadas o descompasso entre a massiva incorporação das mulheres ao mercado de trabalho e o avanço na conquista de direitos, em relação ao acesso a espaços decisórios na política, tem ficado cada vez mais evidente. Dados da InterParliamentary Union ${ }^{2}$ apontam que 21,8\% dos legisladores no mundo são mulheres ${ }^{3}$, que apenas em Ruanda as mulheres são mais de 50\% do legislativo, e que em três países nenhuma mulher faz parte do Parlamento.

Segundo Araújo e Borges (2012), nas eleições de 2010, os candidatos que já eram deputados federais tiveram sete vezes mais chances de sucesso eleitoral do que os que não ocupavam cargo eletivo. Esse dado reforça os achados de grande parte da literatura que aponta que um dos capitais políticos mais importantes em termos eleitorais, é o êxito eleitoral pretérito. Considerando que a entrada das mulheres na arena de disputa é mais recente, este elemento, quando combinado a outros de natureza institucional, bem como referentes à divisão sexual do trabalho, e à perpetuação do

\footnotetext{
${ }^{1}$ Doutoranda em Ciência Política no Instituto de Estudos Sociais e Políticos (IESP), da Universidade do Estado do Rio de Janeiro. Email: tassiaacad@gmail.com.

${ }^{2}$ Fonte: www.ipu.org. Acessado em: 15 de dezembro de 2014.

3 Trata-se da combinação da porcentagem de mulheres nas Câmaras dos Deputados e Senado, quando este existe.
} 
machismo na sociedade, perfazem um quadro complexo no qual o enfrentamento à subrepresentação feminina em espaços de poder se apresenta como um grande desafio.

Neste ponto, os partidos políticos que na maior parte do mundo são responsáveis pela definição das candidaturas, alocação de recursos valiosos, e pelo ordenamento das listas quando estas são fechadas ou flexíveis, podem cumprir um papel fundamental no incremento à participação política feminina. Para além de suas funções suficientemente relevantes para justificar um estudo sobre a participação feminina no interior dessas organizações, levantamos a hipótese de que a maior participação de mulheres em espaços de direção partidários pode servir como uma oportunidade de construção do capital político necessário para que esta venha a disputar e ganhar eleições. Outro ponto importante é que o aumento da presença de mulheres em espaços de direção pode lhes render maior capacidade de influência no processo de tomada de decisões deste ator central para conformação da arena e das oportunidades eleitorais.

Considerando os elementos expostos acima, faremos um estudo de caso sobre os à participação política das mulheres no interior do Partido dos Trabalhadores. O recorte analítico se deu em virtude deste ser o maior partido de esquerda do Brasil, primeiro da América Latina a adotar cotas de gênero, e recentemente, a aprovar a paridade de gênero na composição das suas direções.

\section{Metodologia}

Utilizamos como recursos metodológicos entrevistas fechadas e abertas, pesquisas de opinião, e documentos e jornais internos do Partido dos Trabalhadores. Esta pesquisa teve pretensão e orientação censitária, e buscou traçar as características predominantes dos dirigentes nacionais do PT que tomaram posse após a implantação da paridade de gênero, em dezembro de 2013.

Ao longo de sua elaboração utilizamos fontes primárias e secundárias. No primeiro caso fizemos algumas entrevistas abertas e em profundidade com mulheres dirigentes do partido ${ }^{4}$, construímos um questionário auto aplicado por meio da ferramenta Google Drive ${ }^{5}$, e realizamos pesquisa biográfica sobre os membros do $\mathrm{DN}^{6}$.

\footnotetext{
${ }^{4}$ Essas entrevistas foram realizadas durante a construção da minha dissertação.

${ }^{5}$ As perguntas foram organizadas em blocos e, em sua maioria, tiveram perfil fechado. Questionário completo no Anexo I.

UFSC, Florianópolis - http://dx.doi.org/10.5007/1806-5023.2016v13n1p65 ISSN: 1806-5023
} 
Recebemos 24 respostas ao questionário, e tivemos acesso aos dados gerais da ampla maioria dos dirigentes. Fonte de natureza secundária, os dados referentes às lideranças intermediárias foram produzidos pelo Núcleo de Opinião Pública da Fundação Perseu Abramo (FPA).

Realizamos ainda pesquisa no acervo Sérgio Buarque de Holanda da FPA, que se deu por meio da leitura de jornais, revistas e documentos partidários, e nos permitiu realizar um levantamento da composição das direções nacionais do PT ao longo da sua história, e analisar a trajetória da participação feminina.

A escolha da análise da composição das direções nacionais se deu em função deste ser o mais alto espaço na hierarquia partidária e, portanto, o de mais difícil acesso. Partimos do pressuposto de que, caso tenha havido alterações relevantes na participação das mulheres, a direção nacional do partido necessariamente seria afetada e a análise da sua composição e funcionamento nos permitiria ter uma visão mais geral sobre os impactos no partido como um todo.

Os encontros mais massivos trouxeram elementos importantes para a análise, pois apesar de se tratar de um grupo muito mais amplo que a elite dirigente, é um espaço de representação em que as mulheres passaram por filtros municipais e estaduais para assumirem a posição de delegadas. A análise desses encontros também foi importante para compreendermos o que há em comum no perfil dessas mulheres e daquelas que foram afetadas pela paridade, dado que, até o IV Congresso do PT (2011), as cotas não eram válidas para os encontros e congressos do partido.

\section{Aspectos Institucionais da Sub-representação Feminina no Brasil}

A inserção das mulheres na vida política e nas instâncias de poder é informada por uma série de fatores que não se limitam aos aspectos institucionais, mas ainda assim o desenho institucional é fundamental para as possibilidades de enfrentamento a subrepresentação feminina. Por essa razão faremos um breve apanhado do contexto institucional brasileiro.

\footnotetext{
${ }^{6}$ A pesquisa foi realizada por meio de informações básicas coletadas na Secretaria Geral do PT, e incrementadas a partir de dados do Tribunal Superior Eleitoral, sites dos políticos e páginas no Facebook.

UFSC, Florianópolis - http://dx.doi.org/10.5007/1806-5023.2016v13n1p65 ISSN: 1806-5023
} 
O tipo de sistema eleitoral adotado influencia diretamente o resultado final das eleições, pois define o critério de computação dos votos e estabelece incentivos diferenciados aos eleitores e aos políticos (NICOLAU, 2004). Ao investigar o processo de coordenação eleitoral empreendido pelas elites políticas, Cox (1997) afirma que um dos principais efeitos das eleições majoritárias para a competição política é elevar o custo de entrada nas arenas eleitorais levando a uma redução do número de competidores. Dado que neste sistema a derrota alija o partido do espaço de poder durante todo o mandato, as táticas adotadas visam reduzir ao máximo as possibilidades de fracasso, seja por meio de coligação, ou do investimento em candidatos "bons de voto". Estes, por sua vez, costumam ser aqueles que já possuem mandato, extensa trajetória partidária ou atuam como lideranças associativas. Em geral, mulheres, negros, jovens e grupos minoritários não possuem este capital político, e nem ocupam posições na sociedade que os configurem como os melhores candidatos para atingir o eleitor mediano, e por esses motivos, tem maiores dificuldades de serem candidatos e por conseguinte, eleitos.

O sistema eleitoral proporcional é apresentado como mais favorável ao incremento à participação de grupos minoritários, pois as listas comportam vários nomes e é pragmaticamente atrativo para os partidos lançar candidatos que atinjam os mais variados setores da sociedade. Neste tipo de sistema a maior dificuldade para as mulheres não é a de se tornar candidata, mas sim de ter condições políticas e materiais de disputar de forma competitiva a eleição.

O sistema de lista fechada tem sido considerado o mais favorável a eleição de mulheres (MATLAND, 2005), pois ao invés de fomentar a competição intrapartidária e se basear em características individuais do candidato, possibilita o voto no partido e o esforço conjunto de seus correligionários para que a legenda consiga eleger o maior número de candidatos. Apesar desse diagnóstico, devemos considerar que em sistemas cujas legislações não versam sobre regras de ordenamento da lista, a lista fechada pode ter o efeito contrário. Partidos oligarquizados com decisões tomadas de forma unilateral podem impedir que novos atores adentrem as listas em posições competitivas.

$\mathrm{Na}$ disputa dos cargos do executivo em todas as esferas, e do Senado, o sistema eleitoral brasileiro é majoritário, enquanto nas eleições para vereadores, deputados estaduais e deputados federais, o sistema é proporcional. Para os cargos legislativos, há 
possibilidade de reeleição ilimitada, elemento importante para a perpetuação da subrepresentação feminina, pois as mulheres, minoria absoluta em espaços de representação política, disputam com mandatários detentores de capital político e material diferenciado em virtude do cargo que ocupam.

A ausência deste capital político por parte das mulheres se revela em temos materiais, exemplo disso são os dados trazidos pela pesquisa de Sacchet e Speck (2012) que apontam que em 2006, para o cargo de deputado estadual, as mulheres arrecadaram, em média, $15 \%$ a menos do que os homens, e as candidatas a deputadas federais $45 \%$ a menos do que os homens. Em 2010, a diferença aumentou, a arrecadação das mulheres candidatas a deputadas estaduais foi $37 \%$ menor do que a dos homens, enquanto as candidatas a deputadas federais tiveram uma arrecadação 53\% inferior à dos homens.

Após quase duas décadas de implementação das cotas de gênero no Brasil, os resultados seguem residuais (ARAÚJO, 2004; ARAÚJO; ALVES, 2007), mas diferenciados segundo a esfera de disputa. Em 1992 as mulheres eram 7,4\% dos vereadores, em 1996, primeira eleição realizada após a criação das cotas de gênero para disputa da vereança, o total passou de 3.952 para 6.598 , alcançando $12 \%$ dos vereadores eleitos naquele ano, sugerindo que no âmbito local o incentivo à candidatura feminina proporcionado pelas cotas surte mais efeito, ainda que o total de eleitas siga sendo baixo.

Levantamos a hipótese de que o crescimento, ainda que modesto, encontrado nos cargos eletivos municipais, pode ser explicado pela diferenciação da dinâmica política nos municípios. Nesse âmbito as mulheres tendem a se constituir como sujeitos políticos por meio da participação em atividades comunitárias, da relação com familiares, colegas de trabalho e vizinhos, e a demanda por recursos financeiros para a campanha é mais baixa. Nesse sentido a lei de cotas pode ter proporcionado a essas mulheres, incentivos e oportunidades para que estas se lançassem candidatas diante de uma situação em que sua base eleitoral já existia, mas que sem as cotas seguiria sendo mobilizada por uma candidatura masculina.

Atualmente, o Senado é a esfera de poder com o maior número de mulheres eleitas, elas representam $13,6 \%$ dos assentos ${ }^{7}$. A princípio, este dado vai de encontro à hipótese de que o sistema majoritário dificulta a eleição de mulheres quando comparado

${ }^{7}$ Conforme: tse.jus.br. 
ao proporcional. No caso do Senado brasileiro o modelo de eleição majoritário de um turno seria ainda mais nocivo à participação feminina, pois é sabido que neste sistema a tendência é que menos candidatos concorram, pois os partidos têm apenas um momento para negociar as alianças, e os eleitores utilizam com mais frequência o voto útil. Chama ainda mais atenção o fato apontado por Wright, Azevedo e Santana (2012) de que o desempenho das mulheres é melhor quando a renovação do Senado é de um terço, tal como em 1994, 2002 e 2010.

Considerando que dentre as 27 senadoras eleitas até o ano de 2014, 11 eram filiadas ao PT na ocasião de sua eleição e outras 04 a partidos de esquerda, é possível inferir que há influência de fatores ideológicos, e que mesmo que o sistema majoritário influencie negativamente no lançamento de candidaturas femininas, quando estas se tornam candidatas recebem apoio dos seus partidos, em especial quando há apenas uma vaga em disputa e, portanto, não está colocada a chance de concorrência intrapartidária.

Analisando o sistema eleitoral brasileiro e os resultados aquém do esperado após a implementação das cotas, Araújo (2004) aponta que apesar da centralidade das cotas, em países com lista aberta como o Brasil, estratégias de igualdade de oportunidade, que estabeleçam condições para que as mulheres desenvolvam suas carreiras políticas, podem ser tão eficazes quanto às de desigualdade positiva.

\section{Indo Além das Instituições}

Nós queremos dizer, primeiramente, que o que acontece na vida pessoal, particularmente nas relações entre os sexos, não é imune em relação à dinâmica de poder, que tem tipicamente sido vista como a face distintiva do político. E nós também queremos dizer que nem o domínio da vida doméstica, pessoal, nem aquele da vida nãodoméstica, econômica e política, podem ser interpretados isolados um do outro (OKIN, 2008)

A queda das barreiras formais à participação política feminina é extremamente recente. No Brasil, o direito ao voto e à representação parlamentar das mulheres se deu apenas a partir de 1932. Com um curto interstício democrático entre o Estado Novo e a Ditadura Civil-Militar, a sub-representação feminina no legislativo e a ausência de mulheres nos primeiros escalões da política se manteve. Apenas no ano de 1982 uma mulher chefiou pela primeira vez um ministério, em 1990 foram eleitas as primeiras 
senadoras, em 1994 a primeira governadora e em 2010 a primeira presidenta da república. Este histórico, conjugado à permanência, ainda que remodelada, do sexismo, fez com que a conquista do sufrágio feminino não fosse suficiente para que as mulheres compartilhassem os espaços de poder com os homens.

A divisão entre esfera pública e privada, separou o trabalho produtivo, realizado pelos homens, do reprodutivo empreendido pelas mulheres, o doméstico do político. Tal como Okin (2008), consideramos que esta divisão é um constructo social com funções ideológicas, e que há uma interpenetração entre essas esferas. As decisões tomadas em uma influenciam diretamente a outra, a vivência em uma se reflete na outra. Pateman (1989) aponta que foi por meio desta rígida divisão que o liberalismo justificou a exclusão metade da população mundial do acesso à justiça e igualdade. $\mathrm{O}$ argumento era de que no mundo privado, o poder do marido sobre a esposas e os filhos seria de ordem natural, e portanto atenderia a regras distintas das da esfera pública.

Fraser (2001) elabora um modelo no qual o não-reconhecimento e a subordinação de status se dá quando padrões institucionalizados de valor cultural constituem alguns atores como inferiores, excluídos ou invisíveis. Nesse sentido a ausência de reconhecimento não se limita a uma esfera individual, e sim a uma relação institucionalizada de violação da justiça que impede a participação paritária na sociedade. Essas autoras feministas sublinham que a esfera pública, política, é um espaço generificado, no qual há uma assimetria fundante entre mulheres e homens em que estes são reconhecidos superiores.

A distribuição desigual de recursos financeiros e do tempo no interior da família tem consequências negativas ao engajamento político das mulheres (Phillips, 1991). A manutenção da esfera privada como âmbito de responsabilidade exclusiva da mulher, mesmo diante de sua incorporação no mercado de trabalho, e a existência de poucos mecanismos de responsabilização do Estado nessa esfera, dificulta a construção das carreiras políticas femininas e sua participação em espaços de poder. Pateman (1989) ressalta ainda que a negligência com a família, comumente desculpada quando se dá em função da construção de uma trajetória de sucesso por um homem, é penalizada quando quem busca este objetivo é uma mulher.

Spelman (1988) discute como em cada sociedade a construção dos estereótipos de gênero se diferencia, e aponta que as mulheres que não agem de acordo com os 
papéis estabelecidos recebem algum nível de punição, nos remetendo aos incentivos e desincentivos à atuação política, aos elementos que envolvem a escolha por se candidatar ou não a um cargo eletivo, e a ter ou não uma vida partidária orgânica.

Dados da pesquisa "Mulher na Política" realizada pela SPM em 2002, apontam que a predisposição para se candidatar a cargos públicos eletivos é mais baixa entre as mulheres. Enquanto $28 \%$ dos entrevistados do sexo masculino se candidatariam a qualquer cargo, apenas 19\% das mulheres fariam o mesmo. Quando questionadas sobre quais cargos gostariam de concorrer, o de vereadora é o mais citado (8\%), seguido do cargo de prefeita (4\%). Segundo os dados da mesma pesquisa, 61\% dos homens afirmam que apoiariam a esposa ou companheira a ocupar um cargo de chefia ou tomada de decisão. Dentre esses, $43 \%$ as incentivariam a se candidatarem a vereadoras, $19 \%$ a prefeitas e apenas $13 \%$ dariam apoio independente do cargo em disputa. No que se refere aos cargos de deputada estadual, federal, senadora e presidenta, menos de $10 \%$ dos homens afirmam que apoiariam a decisão de suas companheiras em se candidatar.

O artigo de Araújo e Borges aponta que a família opera simultaneamente como estímulo e contenção ao ingresso na política, e que há uma evidente diferenciação valorativa segundo o gênero em questão. Se por um lado a presença de familiares políticos em cargos públicos entre os homens é maior ${ }^{8}$ e tem servido como incremento ao capital político destes, por outro a figura que tem sido apresentada pelas mulheres como maior expressão de resistência à sua participação política é a do marido. Os autores também apontam que há distinções entre as razões apontadas para a resistência das mulheres a se inserirem ou seguirem com a vida política, e sete em cada dez mulheres escolheram a opção: "perda de tempo para a família".

A pesquisa “Como os Parlamentares Pensam os Direitos das Mulheres?” (2009) nos permite comparar o perfil de legisladoras e legisladores do Congresso Nacional. As diferenças de perfil com relação a estado civil e número de filhos nos remetem à dificuldade enfrentada pelas mulheres para adentrar o mundo da política e os efeitos da divisão sexual do trabalho. Dentre os homens apenas $16 \%$ eram solteiros ou divorciados, no caso das mulheres essa proporção subia para $42 \%$. No que tange ao

\footnotetext{
${ }^{8}$ Esse dado também é apontado pelo artigo: "Assimetrias de gênero nas campanhas eleitorais para a Câmara Federal" de Maria das Dores Campos Machado e Rosanete Steffenon (2010).

UFSC, Florianópolis - http://dx doi.org/10.5007/1806-5023 2016v13n1p65 ISSN: 1806-5023
} 
número de filhos, $22 \%$ das mulheres entrevistadas não tinham filhos, dentre os homens apenas $5 \%$ não eram pais.

O cruzamento dos dados aponta que, enquanto para os homens a conciliação entre vida política e familiar não é um problema, para as mulheres que optam por militar e transcender o espaço local de atuação, muitas vezes é necessário fazer escolhas no âmbito familiar para dar seguimento à construção de uma trajetória política sólida.

Por fim, a violência simbólica sofrida ao longo da vida é aprofundada em espaços de disputa política, e muitas vezes leva as mulheres a acreditarem que não possuem capacidade para assumir espaços de destaque. A dificuldade de se expressar, o medo de ser ridicularizada aparta a mulher do caminho rumo ao poder. Em alguns casos a opção é se limitar ao trabalho de base, em outras é o afastamento por completo dos espaços políticos.

\section{A Política da Presença no PT}

Muitos dos argumentos correntes a respeito da democracia giram em torno do que podemos chamar de demandas por presença política: demandas pela representação igual de mulheres e homens; demandas por uma proporção mais parelha entre os diferentes grupos étnicos que compõem cada sociedade; demandas pela inclusão política de grupos que começam a se reconhecer como marginalizados, silenciados ou excluídos (Philips, 2001).

Segundo estudos fundantes sobre o PT (KECK, 1991; 1992; MENEGUELLO, 1989) o surgimento e crescimento desse partido esteve associado a novas formas de ação social; a um formato de organização interna baseada na aproximação entre a base e as instâncias de direção; e na autenticidade de suas propostas políticas voltadas para setores marginalizados da população.

Trata-se de uma "anomalia", para utilizar os termos de Keck, formada por diversas esferas da sociedade: intelectuais, movimentos comunitários, setores progressistas da Igreja, como pastorais, CEB - Comunidades Eclesiais de Base, e movimentos sociais, dentre esses o feministas, que contou também com ampla base sindical e grupos de esquerda de tradição marxista-leninista, que interferiram para que sua orientação política fundante fosse centrada na luta de classes, enquadrando o racismo, o sexismo, e o preconceito de forma geral como subproduto da ordem 
burguesa, e concluindo que seu enfrentamento passava pela superação das contradições inerentes ao capitalismo.

Dado este contexto inicial e a força desta concepção, ao longo da década de 1980 as feministas tiveram êxito em inserir pautas do movimento no partido, relativizando a hierarquização das lutas. Estas mulheres, envolvidas na construção de um partido que visava inverter as prioridades e dar voz ao "de baixo", demoraram alguns anos para diagnosticar e enfrentar a exclusão feminina nas suas esferas de poder.

No começo do partido havia uma força muito em conjunto com os homens. Havia os sindicatos, igreja, os intelectuais, e as mulheres estavam em todas as áreas e na luta que simbolizava o PT que era uma luta pela igualdade. Em todas essas lutas elas entravam de igual para igual. Isso durou os primeiros anos do partido, na formação do partido. Depois eu acredito que as mulheres foram sendo colocadas no seu lugar, infelizmente. (...) Quase como em uma revolução. As mulheres são chamadas para entrar na guerra, e quando a guerra é ganha os homens assumem o poder, mais ou menos assim. Hoje eu acho que as mulheres estão alijadas do poder no partido. Entrementes, se você for olhar todos os partidos, o PT ainda é o partido em que as mulheres tiveram mais importância, e ainda tem mais importância (Martha Suplicy) ${ }^{9}$

Na primeira década de existência do PT, a participação de mulheres nas direções partidárias revela que as petistas não haviam tido, até aquele momento, sucesso na tarefa de construir um partido em que o poder fosse de fato compartilhado por homens e mulheres. O gráfico abaixo demonstra que a presença feminina na direção nacional do partido era inexpressiva.

Gráfico 1: Percentual de Mulheres e Homens no DN do PT Antes das Cotas

\footnotetext{
9 Trecho de entrevista concedida a Secretária Nacional de Mulheres do PT para a realização do documentário "Muito Prazer, Mulheres do PT".

UFSC, Florianópolis - http://dx.doi.org/10.5007/1806-5023.2016v13n1p65 ISSN: 1806-5023
} 


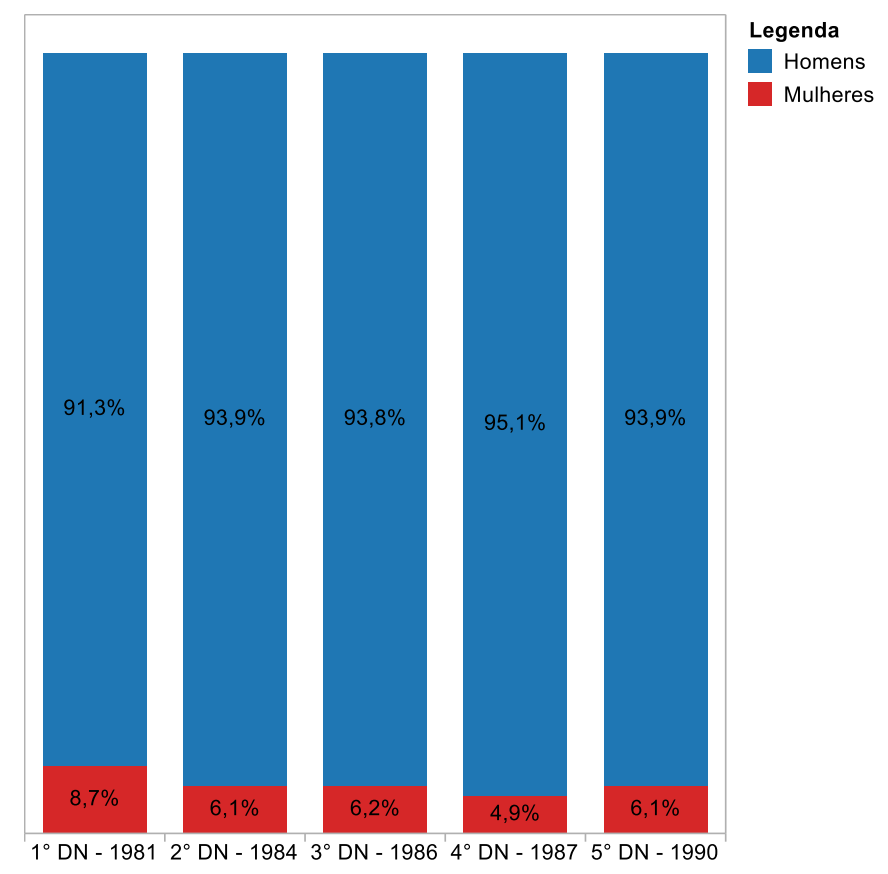

Fonte: Boletim da Subsecretaria Nacional de Mulheres do PT, nov. 1991.

No que se refere à Comissão Executiva Nacional do partido (CEN), a disparidade era ainda maior. Todas as composições da CEN anteriores a introdução das cotas, tiveram a presença de apenas uma mulher, em sua maioria relegadas a posição de suplentes, sendo a gestão eleita em 1987 composta exclusivamente por homens. A primeira militante a ocupar cargo executivo em nível nacional foi Benedita da Silva entre 1990 e 1993. Vale ressaltar que, à época, além de liderança popular do Rio de Janeiro, Benedita era deputada federal, o que fazia dela uma mulher detentora de capital político diferenciado das demais, e a alçava a condição de "apta" a compor este espaço.

Dialogando com essa realidade, em 1988 no II Encontro Nacional de Militantes Petistas do Movimento das Mulheres, iniciou-se o debate sobre a posição ocupada pelas mulheres no interior do partido, tendo sido proposta a introdução das cotas de gênero para a composição das direções partidárias. A proposta foi derrotada por uma pequena margem de votos, voltando a ser discutida no III Encontro, realizado em 1991. Desta vez, a proposta de cotas de gênero foi apresentada como parte de um amplo pacote de ações afirmativas que buscava a ampliação da participação política das mulheres ${ }^{10}$. Em

\footnotetext{
${ }^{10}$ As medidas eram: o reconhecimento da igualdade entre homens e mulheres como um dos princípios gerais do partido, o reconhecimento da organização interna das mulheres como Secretaria, a efetivação de uma política de formação para as mulheres e presença da temática feminista na política geral de formação

UFSC, Florianópolis - http://dx.doi.org/10.5007/1806-5023.2016v13n1p65 ISSN: 1806-5023
} 
seu novo formato a proposta foi aprovada e remetida para a discussão no I Congresso Nacional do PT que, após amplo debate, aprovou que seria garantido na composição dos Conselhos Deliberativos e das Comissões Dirigentes de nível municipal, estadual e nacional do partido uma presença mínima de $30 \%$ de mulheres ${ }^{11}$.

$\mathrm{Na}$ composição das direções nacionais, as cotas mostraram ser um mecanismo de sucesso. No ano de 1993, a participação feminina no DN passou de 6,1\% para $29,8 \%$, um crescimento assombroso que, dado o histórico da presença feminina nesta instância, dificilmente seria alcançado em tão curto espaço de tempo sem as cotas. Apesar do avanço, vale ressaltar que no ano de 1994, quando tomou posse a primeira direção nacional após aprovação das cotas, duas cadeiras não foram preenchidas no ato, demonstrando a dificuldade de adaptação a esse novo processo mesmo três anos após sua aprovação. Na composição seguinte, o percentual de mulheres alcançou os $30 \%$ e se manteve estável. Em 2007, as mulheres voltaram a representar 30\% dos membros do DN, e em 2013, com a paridade, passaram a ser 50\% da Direção Nacional do $\mathrm{PT}^{12}$. Deteremos-nos um pouco mais neste processo.

No ano em que seriam comemorados os vinte anos das cotas de gênero no PT novamente o partido inovou no que tange a participação política das mulheres. Em setembro de 2011 foi realizada a etapa extraordinária do IV Congresso do PT, a primeira etapa, que havia acontecido em fevereiro de 2010 teve um caráter mais próximo a uma convenção eleitoral, sendo a segunda voltada para a reforma estatutária do partido.

No início de 2011 foi estabelecida a Comissão Nacional de Construção, Organização e Reforma do Estatuto, quinze membros que ficaram responsáveis por sistematizar as propostas enviadas pelos filiados e discutir entre as forças políticas a elaboração do texto que seria a base para as votações que iriam a plenário. A princípio a comissão era composta apenas por duas mulheres, ao longo dos trabalhos duas tendências alteraram seus membros e a comissão passou a contar com quatro mulheres e onze homens. A composição inicial da Comissão trata-se de mais um exemplo de que mesmo após duas décadas da existência da reserva de vagas para as mulheres na

do partido e na imprensa partidária, bem como e exigência de creches durante os encontros (GODINHO 1998).

${ }^{11}$ A regra não foi estendida a esses processos, estabelecendo nos anos seguintes uma incongruência entre a presença feminina na cúpula em relação a sua participação nos Encontros Nacionais.

12 Excetuando do cálculo os líderes do PT no Senado e na Câmara. 
direção, a ampliação da presença feminina em espaços não previstos na resolução de cota de gênero segue apresentando dificuldades.

Em abril, a secretária nacional de mulheres apresentou a proposta de paridade de gênero para a Comissão de Reforma do Estatuto. A proposta se diferenciava das cotas aprovadas em 1991 não apenas na proporção de mulheres que passariam a assumir cargos na direção, mas também porque se tratava de uma medida que seria válida para as direções, comissões, delegações e divisão de cargos na executiva.

Ao longo do primeiro semestre foram estabelecidas rodadas de negociações relativas à proposta inicial. $\mathrm{Na}$ Comissão foi colocada a proposta de manutenção dos $30 \%$ e três formatos de proposta de paridade. Para além da proposta apresentada pela secretária de mulheres foi encaminhada por outro membro da direção uma proposta de paridade exclusiva para as direções, e uma mediação defendida pelo coordenador da Comissão, Ricardo Berzoini, que previa a aprovação imediata de $40 \%$ de mulheres nas direções para os dois próximos PED's (2013 e 2017) seguida da implantação da paridade no terceiro PED após o Congresso (2021).

Em entrevista realizada anteriormente ao IV Congresso, a secretária nacional de mulheres Laisy Moriére relata que aceitou a proposta de mediação com ressalvas. Afirma que concordou com a aprovação imediata dos $40 \%$ para o primeiro PED após a reforma do estatuto, em 2013, seguida de 50\% no PED posterior a este e não no terceiro como previa a proposta inicial, além disso, incluiu a paridade nas delegações, comissões e cargos da executiva. Dessa forma, relata ter conseguido construir maioria na Comissão, na qual todos se posicionaram a favor da proposta mediada com exceção de dois membros que mantiveram seu posicionamento contrário a ampliação dos $30 \%$.

A despeito da decisão da Comissão, para ser aprovada a proposta deveria ser encaminhada ao plenário do Congresso e votada pelos delegados presentes. Dado o grau de controvérsia que a proposta envolvia Laisy afirma que as mulheres precisariam constranger os que se opunham a proposta para que esta fosse aprovada. Em se tratando de um processo cuja votação da maioria das medidas não é secreta, se dá por contraste visual de crachás, tal estratégia poderia ser útil.

Entre 02 e 04 de setembro, 1.350 delegados se reuniram em Brasília para discutir as reformas no estatuto do PT. O Congresso do PT, instância máxima de deliberação do 
partido tinha poderes para alterar no estatuto qualquer ponto que os delegados considerassem necessários, e assim o fez com as cotas de gênero.

Diferente do que se esperava, o acordo firmado entre a secretária de mulheres e a coordenação da Comissão foi atropelado por mulheres que adentraram o plenário gritando o lema "paridade já". A estratégia do constrangimento que Laisy já havia dito ser necessária para aprovar a medida foi utilizada, e mesmo que o processo tenha indicado que as discordâncias eram muitas, a resolução foi aprovada por aclamação do plenário.

No ato de sua aprovação as cotas foram apresentadas como medidas transitórias, que viriam a ser superadas quando o partido tivesse na prática a participação equitativa das mulheres. A aprovação da paridade de gênero demonstra que tal objetivo não foi alcançado.

\section{As Cotas e a Paridade de Gênero na Prática}

Tatau Godinho, que compôs a primeira executiva do PT após a introdução das cotas, relata que durante o processo de formação do primeiro $\mathrm{DN}$, as mulheres precisaram se organizar para conter a proposta de ampliação do número de cadeiras, que visava à manutenção dos homens que antes da cota ocupavam esse espaço. Afirma que tal ação foi vitoriosa, mas que se deu em meio a muitas dificuldades, pois não era simples para a direção do partido substituir os mais de vinte homens que a resolução previa. Uma forma utilizada para seguir acomodando os homens em cargos de direção foi a de transferir cargos tipicamente da CEN para o pleno, composto pelos membros do DN sem função executiva. Nas direções seguintes a prática foi abolida, mas se repetiu na atual gestão (2013-2017), primeira paritária.

No que tange a primeira composição da CEN, Tatau registra ter havido a tentativa de interpretar a resolução de cotas como sendo limitada a direção como um todo e afirma que as mulheres não aceitaram tal artifício e a executiva precisou ser composta por no mínimo $30 \%$ de mulheres. Relata que outra tentativa sem êxito de relativizar a medida foi a de separar o presidente do partido do cálculo das cotas. A única exceção aceita pela direção das mulheres do partido a época foi referente aos líderes de bancada, pois estes podem variar ao longo de uma mesma gestão. $\mathrm{Na}$ CEN as 
mulheres passaram a representar $36,8 \%$ na primeira gestão pós-cotas, percentual que seria o pico de sua representação neste espaço até 2013.

Visando compreender as dinâmicas de poder no PT e a influência das mulheres, estabeleceremos uma tipologia que facilitará o mapeamento da participação das mulheres não apenas na instância, mas nos centros de poder da organização petista. $O$ DN, que é composto por membros que possuem funções indiferenciadas, desempenha o papel de deliberar sobre todo o tipo de assunto concernente a vida partidária. A Executiva, subordinada ao Diretório, tem como atribuição pôr em prática as deliberações do DN.

Dividiremos a CEN em quatro categorias: núcleo duro, núcleo expandido, cargos consultivos e representantes de setoriais e secretarias. O núcleo duro é composto pelos cargos que ocupam maior posição de destaque e responsabilidade na direção do partido. São parte deste, a presidência, que responde pela representação pública do partido, e as Secretarias de Organização, Geral e de Finanças, que desde o primeiro regimento do PT possuem status diferenciado das demais. O núcleo expandido é composto por cargos que cumprem funções executivas específicas na direção e, tal como o núcleo duro, estrutura financiada pelo PT para exercer suas atividades. Fazem parte deste núcleo as Secretárias de Assuntos Institucionais, Mobilização, Movimentos Populares, Formação Política, Relações Internacionais e Comunicação. Os cargos que denomino de consultivos não exercem funções no partido, mas tem direito a voto na executiva, são estes: as vice-presidências e as vogais.

Por fim, algumas secretarias e setoriais compõe a executiva do partido, mas com direito apenas a voz, influenciando nas decisões de maneira indireta. Com base na estrutura explicitada acima podemos perceber a existência de uma hierarquia nítida entre os cargos da CEN, nesse sentido, consideramos importante verificar quais cargos foram ocupados pelas mulheres que chegaram a Direção Nacional do PT.

O mais alto cargo da hierarquia partidária, a presidência, jamais foi ocupado por uma mulher, e apenas duas o disputaram. Em 2005, Maria do Rosário e em 2009 Iriny Lopes. Vale destacar que à época, ambas eram deputadas federais e posteriormente foram alçadas a ministras no Governo Dilma. A primeira filiada a ocupar o núcleo "duro" do partido foi Tatau Godinho que chefiou a Secretaria de Organização entre 
1993 e 1995, depois desta, apenas Clara Ant ocupou um posto-chave na CEN, a Secretária Nacional de Finanças durante duas gestões, entre 1995 e 1999.

$\mathrm{Na}$ gestão 2013-2017, dentre as mulheres que compõe a Executiva Nacional nenhuma faz parte do núcleo duro. O núcleo expandido por sua vez, é composto por quatro mulheres, um avanço com relação à gestão passada, em que havia apenas uma, e as demais ocupavam cargos consultivos ou representavam secretarias. Vale ressaltar, porém, que duas secretarias com pouca expressividade foram criadas para acomodar as mulheres que assumiriam a executiva a partir da paridade, não por acaso estas são ocupadas por duas, dos quatro jovens que cumprem as cotas geracionais na CEN.

Esses dados demonstram que, apesar das cotas, os cargos de maior importância na direção nacional do partido seguem sendo ocupados por homens, salvo raras exceções. Vale ressaltar ainda o relato de algumas entrevistadas que apontam situações em que vagas do DN são formalmente ocupadas por mulheres, mas não politicamente. São citados exemplos em que os homens cumprem as funções políticas que deveriam ser de incumbência da mulher que assumiu o cargo e casos em que estas sequer participam das reuniões, sendo substituídas por suplentes do sexo masculino.

Nós fizemos muito esforço naquela época [1993] para que as mulheres assumissem cargos efetivos reais de direção, tinha muito mais na primeira gestão de cotas do que o que foi se consolidando depois, que foi essa rasteira de que as mulheres ficam no coletivo geral, mas não assumem responsabilidades ou quando assumem não assumem de fato, assumem a titularidade da coisa, mas não assume de fato (Tatau godinho $)^{13}$.

Conceição Nascimento, quatro vezes Secretária Nacional de Mulheres do PT, relata as dificuldades que acompanhou durante a montagem dos DN dos quais fez parte e afirma que há diferença de priorização entre homens e mulheres mesmo no mais alto espaço de direção do partido.

Já vi montagem de DN e sei como é. Como é que o Aloizio Mercadante não vai ficar no diretório? Como é que o Zé Dirceu não vai ficar? Como é que o fulano de tal não vai ficar? Ninguém pergunta assim, como é que a Fátima Cleide não vai ficar? Como é que fulana não vai ficar? Ou então diz assim, o Norte pode indicar alguém para o

\footnotetext{
${ }^{13}$ Entrevista realizada pela autora com Tatau Godinho.
} 
diretório, mas tem que ser uma mulher. É uma moeda de troca e é quase um castigo ás vezes (Conceição Nascimento).

Passados vinte anos é possível afirmar que o espaço das mulheres no interior do PT foi ampliado e que isso permitiu, ao menos nesse quesito, uma maior democratização do partido. Apesar disso discute-se que as cotas, que foram criadas para garantir o mínimo de $30 \%$ de mulheres nas direções, se transformaram em um teto.

Os dados são flagrantes dessa realidade, pois passados sete processos eleitorais após o I Congresso as mulheres não conseguiram chegar à marca de $31 \%$ da direção nacional do partido, dando elementos concretos para o registro feito por algumas entrevistadas que afirmavam que em alguns casos as cotas haviam se tornado um instrumento meramente burocrático ao invés de um mecanismo de promoção real da participação das mulheres.

Com a primeira gestão paritária completando dois anos, é importante relatar que a nova regra foi cumprida, tal como a proporcionalidade étnico-racial e a cota geracional, apesar de seu avanço na garantia da presença de mulheres nos espaços de direção, seu impacto substantivo ainda precisará ser avaliado com mais detalhe em outra pesquisa, neste aspecto, por ora, limitaremos nossa análise aos entraves à representação substantiva das mulheres ao longo das duas décadas de implementação das cotas de $30 \%$.

\section{Os Entraves à Representação Substantiva e ao Sucesso Eleitoral das} Mulheres

Duverger (1970) aponta que em oligarquias abertas, a renovação ocorre inicialmente no interior do partido e posteriormente no âmbito do governo e no legislativo, quando essa nova elite partidária conquista a vitória eleitoral. Araújo e Borges (2012) afirmam que compor a direção partidária pode constituir importante estímulo e base para a disputa eleitoral, e que quatro em cada cinco eleitos para a Câmara dos Deputados em 2010 ocupavam cargos em seus respectivos partidos.

No caso do PT, independentemente do tamanho de sua bancada, o partido sempre figurou entre os três da Câmara com a maior proporção de mulheres eleitas. Durante as três décadas que se passaram, em apenas duas ocasiões o número de 
mulheres petistas na Câmara dos Deputados diminuiu. Em geral, foi possível identificar o crescimento em números absolutos das mulheres eleitas, no entanto, a proporção de mulheres com relação ao total de deputados homens eleitos do PT nunca chegou a ultrapassar sua marca original de $25 \%$ em 1982. Os dados demonstram que as mulheres não acompanharam o crescimento do partido, e que a despeito das petistas ocuparem 30\% dos cargos de direção do PT desde 1993, sua atuação interna não se reverteu em resultados consistentes na proporção de eleitas para a Câmara dos Deputados.

Gráfico 2 - \% de Mulheres Eleitas Deputadas Federais do Total de Eleitos do PT

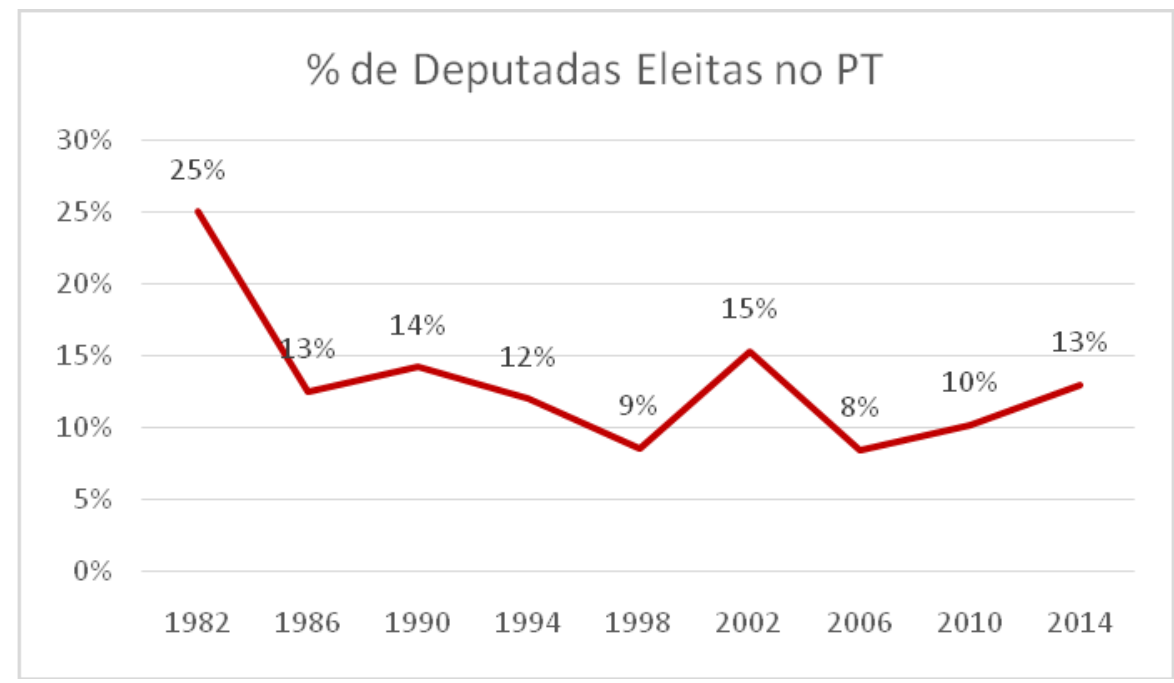

Fonte: Tse.jus.br

As entrevistas apontaram que, apesar das mulheres terem garantido sua presença nas direções, esse elemento não alterou significativamente a estrutura destinada às campanhas das petistas. Se por um lado parte relevante do financiamento das campanhas proporcionais é oriundo de doações externas ao partido, no âmbito partidário, os recursos são divididos por meio de instâncias informais as quais as cotas não possibilitaram o acesso às mulheres. Ainda assim, Araújo e Borges relatam que nos partidos menores e de esquerda, incluindo o PT, o financiamento das campanhas femininas ficou mais próximo ao das masculinas nas eleições analisadas, do que nos demais partidos.

O fato de o Senado apresentar um maior número de mulheres petistas eleitas aponta que a questão do apoio partidário é fundamental para as chances eleitorais. Neste caso, por se tratar de uma disputa majoritária, as mulheres têm mais dificuldades em se UFSC, Florianópolis - http://dx.doi.org/10.5007/1806-5023.2016v13n1p65 ISSN: 1806-5023 
tornarem candidatas quando comparado com os cargos eleitos proporcionalmente, mas com a candidatura estabelecida, a disputa intrapartidária é arrefecida e as mulheres acessam os recursos necessários para disputar as eleições de forma competitiva.

Não é pouco significativo que a primeira Presidenta da República eleita e reeleita seja petista, e que as demais candidatas mulheres à presidência desde 2006: Heloísa Helena, Marina Silva e Luciana Genro, tenham construído sua trajetória partidária nesta legenda. Podemos observar ainda um considerável incremento na participação de mulheres nos ministérios, 10 das 37 pastas de primeiro escalão do Governo Federal foram ocupadas por mulheres em 2010, mudança substancial quando comparada com Governos anteriores ${ }^{14}$.

No que se refere à representação substantiva das mulheres, na ocasião da aprovação das cotas no PT, vários jornais internos afirmavam que estas proporcionariam às mulheres maior entendimento dos mecanismos de poder, possibilidade de intervenção nos espaços políticos, apropriação das discussões do partido, reconhecimento enquanto direção e a criação de novos referenciais para as outras mulheres. Atualmente as avaliações são mais duras:

Nosso espaço de poder, mesmo com a cota tem diminuído. Porque as nossas representações nas direções estão muito caladas. Sempre tivemos mulheres na direção, mesmo antes das cotas em menor número, que se pronunciavam, iam para o embate. Essas mulheres, não é que elas não queiram, mas é que as chapas que delegam qual é a mulher, e normalmente não é aquela que a gente considera melhor preparada, é aquela que concorda, e isso é muito ruim para a gente fazer essa afirmação, mas é o que acontece (...) Então a gente cresce numericamente, mas aumentam as nossas dificuldades internas de estrutura, e aumenta nossa dificuldade em termos de representação de mulheres com mais capacidade de intervenção de discussão, elas estão nas chapas, mas na hora de assumir os cargos não são elas (Cristina Dorigo) ${ }^{15}$.

A fala citada acima e outros relatos coletados nos permitem perceber que as cotas são mecanismos centrais para o crescimento da presença política das mulheres,

\footnotetext{
14 Nos cinco anos de governo Sarney apenas Dorothéa Fonseca atuou como interina no Ministério Trabalho; Fernando Collor escolheu duas mulheres para chefiar seus ministérios; no governo de Itamar Franco a única mulher a assumir uma pasta ministerial foi Luiza Erundina, que comandou a Secretaria de Administração; o primeiro mandato de Fernando Henrique Cardoso contou com uma mulher no gabinete ministerial; quatro anos depois, tomaram posse em seu segundo mandato três ministras; o primeiro mandato de Lula começou com quatro mulheres entre ministérios e secretarias, mas seu governo terminou, em 2010, com apenas duas ministras.

15 Trecho de entrevista com Cristina Dorigo, ex-secretária estadual de mulheres do PT do Rio de Janeiro.
}

UFSC, Florianópolis - http://dx.doi.org/10.5007/1806-5023.2016v13n1p65 ISSN: 1806-5023 
mas não podem ser avaliadas apenas a partir de uma perspectiva numérica. Ter mais mulheres nas direções não significa necessariamente colocar o debate de gênero na pauta do partido. É inegável que o expressivo crescimento da presença de mulheres possibilitou a formação de novos quadros políticos femininos, mas é difícil mensurar quantas mulheres se tornaram dirigentes no sentido estrito da palavra e quantas apenas “cumpriram as cotas". Apesar das críticas, vale ressaltar outra fala de Cristina Dorigo que aponta que as cotas são importantes ainda que sofram distorções: "Mesmo aquelas companheiras que foram lá só cumprir as cotas, que não tem interesse, a gente vai discutindo, vai falando, vai dando material e elas vão mudando, vão mudando o conceito, vão mudando o modo de ser".

Atualmente, uma questão central colocada pelas militantes é a dificuldade das mulheres em ter acesso às redes informais de poder. Se por um lado o acesso às direções partidárias foi garantido por meio das cotas, e mais recentemente da paridade, o poder de decisão no interior das correntes não foi compartilhado na mesma medida.

Eu não vejo esse espaço de poder das mulheres em nenhuma tendência do PT do Rio de Janeiro, nenhuma. A gente pode procurar dentre as tendências do Rio qual que a mulher é a interlocutora, ou faz parte do grupo de interlocução, não tem. Você vê mulheres poderosas, mulheres parlamentares, elas não são interlocutoras do grupo político delas. Mulher "chefona" de estatal, orgânica no partido, mas na discussão interna do partido não é interlocutora; mulheres dirigentes sindicais, mulheres dirigentes da CUT, nenhuma. Então, cadê nosso espaço de poder que agente conquistou que tanto o PT diz que a gente tem? (Cristina Dorigo)

E não existe no PT nenhuma tendência feminista, todas são machistas. $\mathrm{E}$ as tendências só mudam se tiver pressão de mulher, senão tiver não muda... Ali é o espaço político dos homens (Laisy Moriére)

As cotas não conseguiram superar um problema estruturante da dificuldade da participação política feminina que é a valorização no âmbito da política de habilidades pouco desenvolvidas no processo de socialização das mulheres, como falar em público, e exercer e saber lidar com métodos de disputa agressivos. A tripla jornada de trabalho no lar, no mercado e na política - também não pode ser subestimada, principalmente em um partido cujos principais quadros políticos conquistaram espaço a partir da dedicação quase exclusiva à militância. Nesse sentido, dados que apontam a disparidade entre o perfil das mulheres e dos homens delegados (as) aos encontros do partido e integrantes 
da atual composição DN, reafirmam a dificuldade de conciliação entre essas três esferas da vida diante da ausência de divisão de tarefas no âmbito privado e público.

A análise da composição das delegações dos Encontros e Congressos Nacionais do PT dá fortes indicativos do impacto da divisão sexual do trabalho na construção das carreiras políticas das mulheres. Chama atenção que a proporção de mulheres nãocasadas $^{16}$ é significativamente mais elevada do que a dos homens. Os dados referentes ao número de filhos, também indicam a flagrante diferença entre as dificuldades enfrentadas pelas mulheres no âmbito doméstico para militar e os homens. Nestes espaços, a proporção de mulheres sem filhos foi sempre maior do que no total dos delegados, dado que, como vimos anteriormente, também é encontrado dentre as parlamentares.

Gráfico 3: Delegados e Delegadas Petistas: Estado Conjugal e Filhos

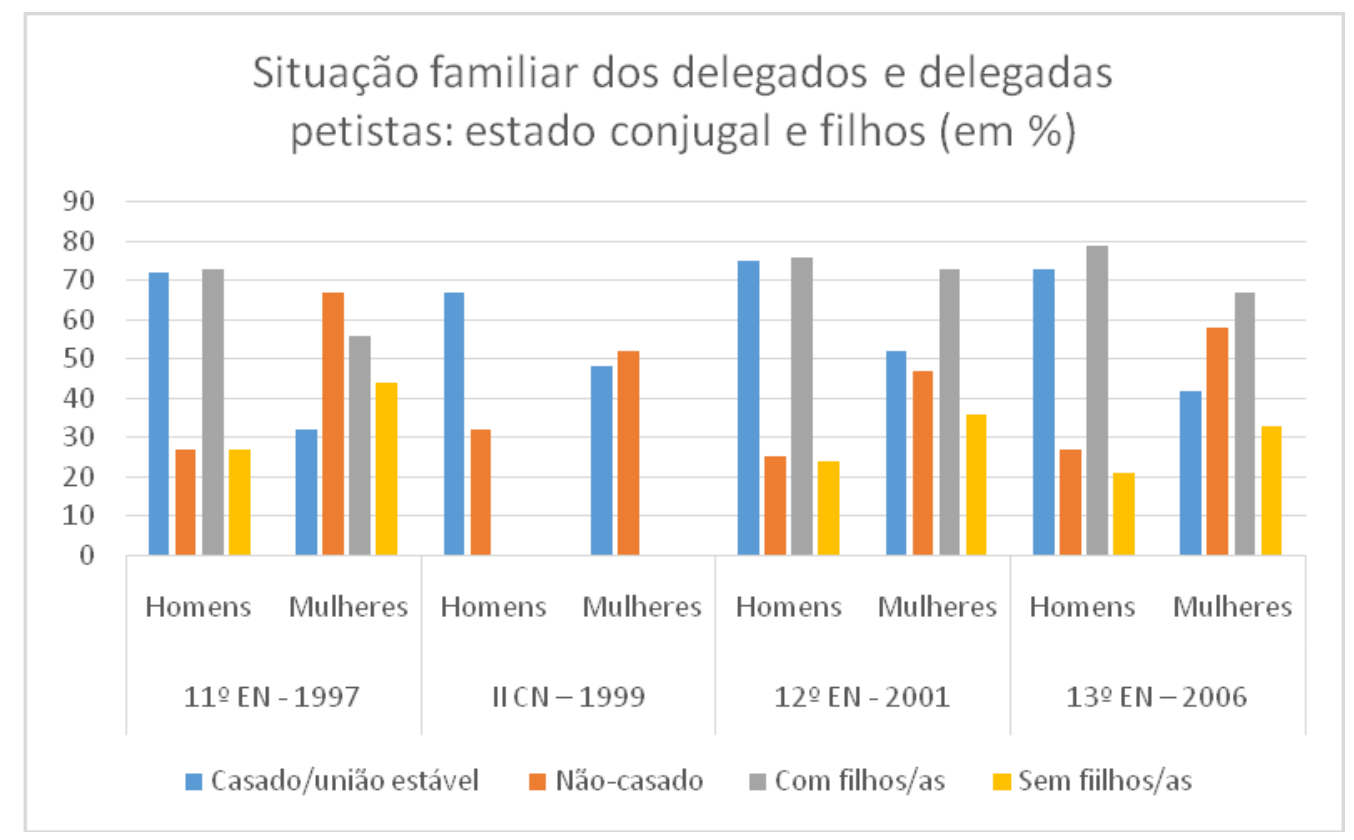

Fonte: Núcleo de Opinião Pública da Fundação Perseu Abramo

A idade dos filhos (as) também é uma informação importante, pois a maioria dos filhos (as) das delegadas que são mães se concentram em faixas etárias maiores, contrastando com os homens delegados. É importante ressaltar que a média de idade

${ }^{16}$ Soma das categorias solteiro (a), separado/divorciado (a), viúvo (a). 
dos delegados não varia significativamente entre os sexos, reforçando o peso diferenciado da situação familiar entre homens e mulheres.

Gráfico 4: Delegados e Delegadas Petistas: Idade dos Filhos ${ }^{17}$

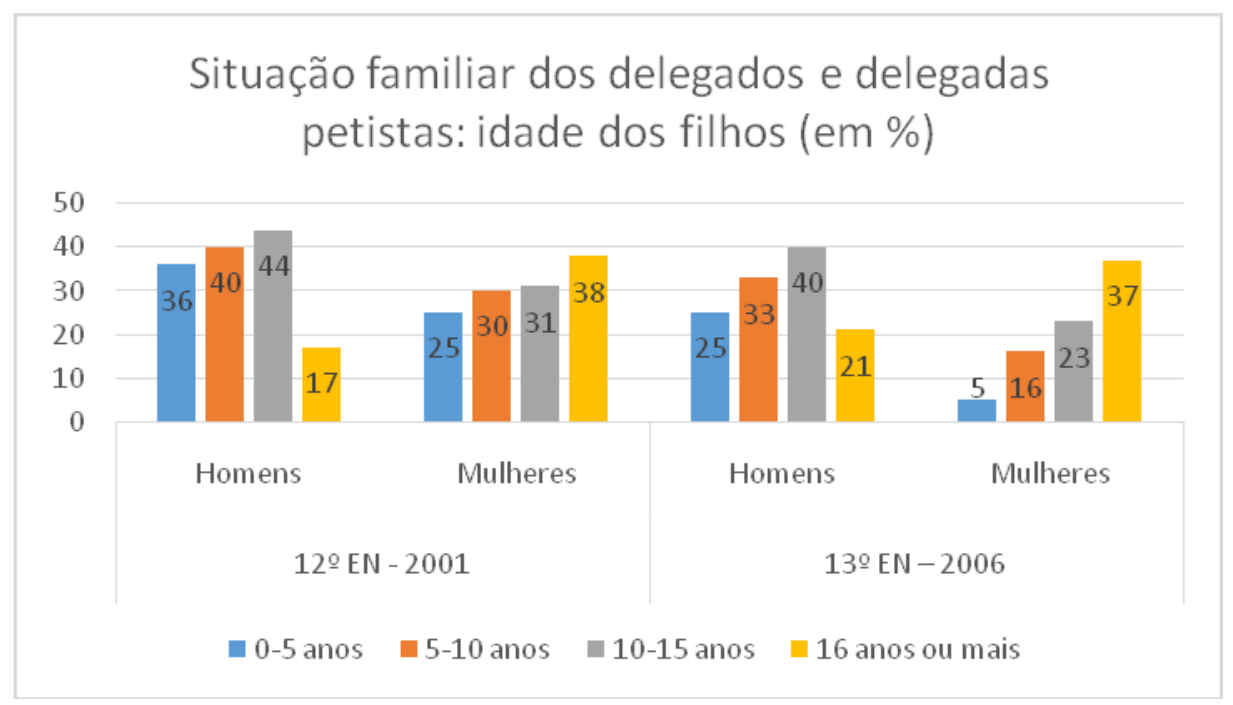

Fonte: Núcleo de Opinião Pública da Fundação Perseu Abramo

Considerado que este é o nível que estamos tomando como intermediário, podemos dizer que mesmo em esferas inferiores na hierarquia partidária o impacto das tarefas diferenciadas entre homens e mulheres na sociedade também pode ser identificado. A mulher não-casada, sem filhos (as), ou com filhos (as) com idade acima dos 15 anos, representa o perfil de militante mais comumente encontrado nessa camada.

A análise do perfil dos integrantes do primeiro DN paritário do PT apontou uma tendência similar à encontrada nos Encontros e Congressos Nacionais do PT. A situação familiar, tanto conjugal quanto com relação a ter ou não filhos, apresentam valores inversamente proporcionais entre homens e mulheres.

Gráfico 5: Integrantes do DN: Estado Conjugal e Filhos (as)

\footnotetext{
${ }^{17} \mathrm{O}$ total ultrapassa $100 \%$ porque as respostas eram múltiplas: delegado com filhos em categorias etárias distintas assinalava mais de uma opção
}

UFSC, Florianópolis - http://dx.doi.org/10.5007/1806-5023.2016v13n1p65 ISSN: 1806-5023 


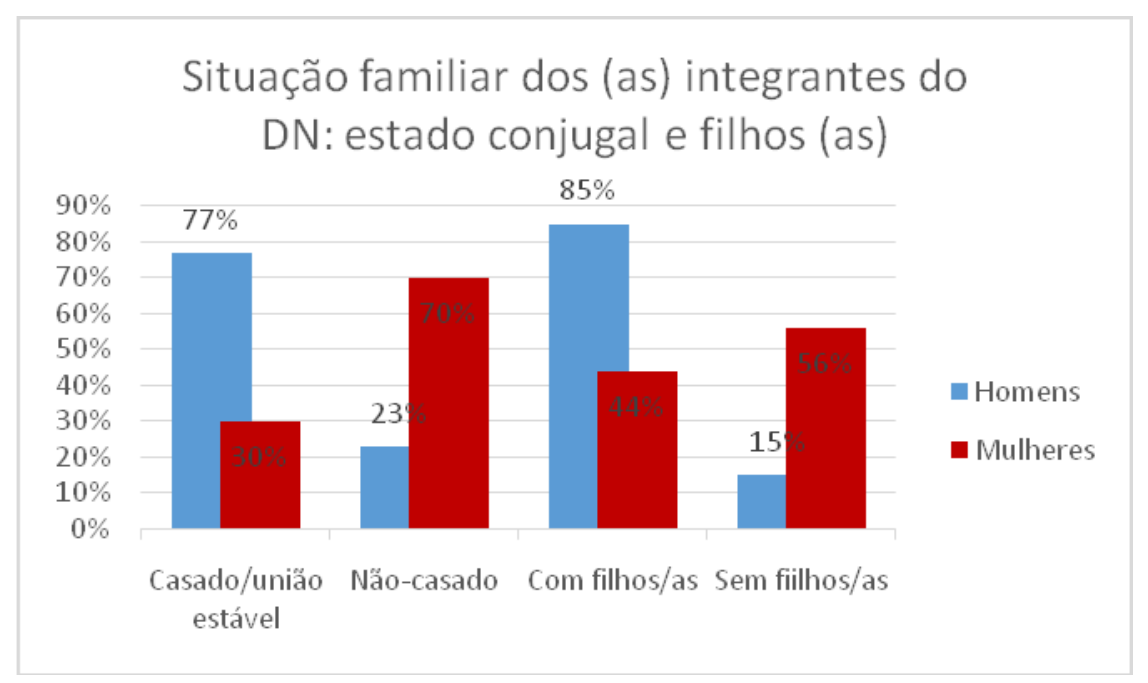

Fonte: Secretaria Geral do PT

Dentre os integrantes do DN, há uma outra diferença bastante expressiva entre homens e mulheres, enquanto ampla maioria dos homens ocupa ou já ocupou cargos eletivos, são poucas as mulheres na mesma situação. Com a necessidade de inserção de mais mulheres nas direções, ser exceção à regra, como vimos no caso de Benedita da Silva na década de 1980, deixou de ser necessário para que mulheres ocupassem essas instâncias. Por outro lado, a redução do espaço destinados aos homens levou a intensificação do fenômeno da parlamentarização do $\mathrm{DN}$, pois durante a definição dos nomes de dirigentes que seriam cortados para que as mulheres assumissem as vagas, os detentores de cargos eletivos tiveram mais peso na negociação.

Esse é um elemento importante, pois tal como a assimetria de poder na sociedade, medida pelos votos conquistados, permitiu que os homens eleitos, e não outros, fossem indicados para o Diretório, este capital político se faz presente nas reuniões da instância e impacta nas relações travadas, no que é ou não considerado nas decisões.

\section{Considerações Finais}

Este artigo apresentou uma breve análise sobre a implementação das cotas de gênero no PT. Apesar de seu sucesso em termos numéricos no partido, as cotas não permitiram o crescimento da participação feminina em outras áreas do partido que não estavam inclusas na resolução, em especial nos espaços informais de poder. 
As entrevistas nos permitiram perceber que há decisões importantes que não são tomadas exclusivamente pelas direções eleitas, as tendências políticas definem o destino dos recursos de campanha, os cargos a serem assumidos, bem como o maior ou menor investimento político em um militante. Nesse âmbito, as cotas influenciaram porque criaram a necessidade de construção de quadros femininos, mas de acordo com os relatos das entrevistadas ainda não possibilitaram que a maioria desses quadros assumissem espaços de direção e tomada de decisão no interior de suas tendências. $O$ crescimento da participação nas instâncias partidárias também não foi acompanhado pela bancada na Câmara dos Deputados, ainda que tenha havido incremento no Senado e no Executivo Federal.

Por meio das análises de dados pessoais dos dirigentes nacionais, e delegados (as) aos Encontros e Congressos Nacionais do PT, discutimos as principais barreiras ao desenvolvimento das carreiras políticas das mulheres quando comparadas aos homens. Os dados reafirmaram que mecanismos intrapartidários de reserva de vagas impactam de maneira rápida e assertiva a composição das direções partidárias, mas isolados não resolvem o problema da representação substantiva, pois há elementos outros, de natureza simbólica e relacionados à divisão sexual do trabalho, que atuam como barreiras à atuação política das mulheres.

Mudanças culturais de grande magnitude ainda são necessárias para que mulheres em todo o mundo se tornem sujeitos políticos plenos. Diante da dificuldade e da lentidão em que se dão mudanças dessa natureza, faz-se necessária a discussão sobre mecanismos alternativos que permitam que não precisemos esperar durante tempo indeterminado para que as mulheres possam se inserir nos espaços de poder. Nesse sentido, as cotas seguem sendo medidas centrais para que as mulheres também se tornem protagonistas no mundo da política.

O processo de disputa que levou a aprovação das cotas permitiu a exposição da desigualdade entre homens e mulheres no interior do partido. Os jornais e boletins que após a aprovação das cotas discutiram a questão de gênero apresentaram os problemas que as mulheres enfrentam para dar continuidade a sua militância e relataram situações de constrangimento que estas sofriam no âmbito do partido. Nesse quesito, as cotas foram centrais por colocar no debate a discriminação que as mulheres sofriam na sociedade e no PT, permitindo uma reflexão coletiva sobre a situação que em vinte anos 
engendrou uma mudança na cultura política e fez com que atitudes machistas se tornassem inaceitáveis no interior do partido.

A presença das mulheres em órgãos de direção criou condições mais propicias para a alteração das relações cotidianas entre homens e mulheres. Tornou-se mais frequente no partido a cobrança para que as mulheres ocupem cargos de representação, ao mesmo tempo em que estas mulheres passaram a ousar fazer a disputa por mais espaço político.

De maneira bastante distinta de outros espaços da política, o DN-PT é pela primeira vez composto por metade de homens e metade mulheres. Considerar isso é reconhecer que há uma maior possibilidade de que a lógica da tomada de decisões no interior do PT seja permeada pelas posições das mulheres, gerando alterações tanto no modo de funcionamento quanto na definição de prioridades e das áreas de interesse assumidas por este partido.

\section{Referências}

ALVES, José E. D.; CAVENAGHI, Sônia. As Mulheres nas Eleições de 2004 e as Limitações da Política de Cotas. Porto Alegre, 2005.

ARAÚJO, Clara; ALVES, José E. D. Impactos de indicadores sociais e do sistema eleitoral sobre as chances das mulheres nas eleições e suas interações com as cotas. Dados 50, 2007.

ARAÚJO, Clara; BORGES, Doriam. O "gênero", os "elegíveis" e os "não-elegíveis": uma análise das candidaturas para a Câmara Federal em 2010. In: ALVES, José E. D.; PINTO, Céli R. J.; JORDÃO, Fátima (Org.) Mulheres nas eleições 2010. São Paulo, 2012.

ARAÚJO, Clara. A Intercessão entre Partidos Gênero e Partidos Políticos no Acesso das Mulheres às Instâncias de Representação. 2004. 
AZEVEDO, Eulália; WRIGTH, Sonia; SANTANA, Joselita. As mulheres na disputa para o Senado no processo eleitoral de 2010. In: ALVES, José E. D.; PINTO, Céli R. J.; JORDÃO, Fátima (Org.) Mulheres nas eleições 2010. São Paulo, 2012.

COX, Gary. Making Votes Count: Strategic Coordination in the World's Electoral Systems. Cambridge, Cambridge University Press, 1997.

DUTRA, Eneida Vinhas; FLEISCHER, Soraya. Como Parlamentares Pensam os Direitos das Mulheres? Pesquisa na Legislatura 2007- 2010 do Congresso Nacional. Brasília, 2010.

Duverger. Os Partidos Políticos. Rio de Janeiro, Zahar, 1970.

FRASER, Nancy. Da redistribuição ao reconhecimento? Dilemas da justiça na era póssocialista. In Democracia hoje: novos desafios para a teoria democrática contemporânea. Brasília, 2011.

GODINHO, Tatau. O PT e o Feminismo. In Mulher e política: gênero e feminismo no Partido dos Trabalhadores, 1998.

IBOPE, e Instituto Patricia Galvão. Mulheres na Politica, 2002.

KECK. PT: a lógica da diferença: o Partido dos Trabalhadores na construção da democracia brasileira. São Paulo, Ática, 1991.

MATLAND, Richard. Enhancing Women's Political Participation: Legislative Recruitment and Electoral Systems. In Women in Parliament: Beyond Numbers, ed. Julie Ballington and Azza Karam. International Institute for Democracy and Electoral Assistance, 2005.

MENEGELLO, R. PT : A formação de um partido : 1979-1982. Rio de Janeiro : Paz e Terra, 1989. 
PHILLIPS, Anne. Engendering Democracy. University Park: The Pennsylvania State University Press, 1991. De uma Política de Ideais a uma Política da Presença? Revista Estudos Feministas, vol. 9, nº 1, 2001.

NICOLAU, Jairo. Sistemas Eleitorais. Rio de Janeiro: FGV, 2004.

OKIN, Susan. Gênero, o público e o privado. Revista Estudos Feministas, vol. 16, no 2, 2008 .

PATEMAN, Carole. The disorder of women. Stanford: Stanford University Press, 1989.

SACCHET, Teresa; SPECK, Bruno. (2012). Dinheiro e sexo na política brasileira: financiamento de campanha e desempenho eleitoral em cargos legislativos In: ALVES, José E. D.; PINTO, Céli R. J.; JORDÃO, Fátima (Org.) Mulheres nas eleições 2010. São Paulo, 2012.

SPELMAN, Elizabeth. Inessential woman: problems of exclusion in feminist thought. Boston: Beacon Press, 1988. 


\title{
As Mulheres Dirigentes do Partido dos Trabalhadores: Perfil e Desafios à Representação Substantiva
}

Resumo: Este artigo trata-se de um estudo de caso sobre a participação política das mulheres no interior do Partido dos Trabalhadores, primeiro partido da América Latina a adotar cotas de gênero e a aprovar a paridade na composição das suas direções. A metodologia de combinou entrevistas abertas e em profundidade com mulheres dirigentes do partido; pesquisa biográfica e aplicação de questionários fechados aos integrantes da atual gestão da Direção Nacional do PT; pesquisas de opinião com os delegados dos encontros e congressos nacionais; levantamento da composição das direções nacionais do PT ao longo da sua história; e análise da trajetória da participação feminina por meio de acesso a jornais e documentos internos diversos. Os dados reafirmaram que mecanismos intrapartidários de reserva de vagas impactam de maneira rápida e assertiva a composição das direções partidárias, mas isolados não resolvem o problema da representação substantiva, pois há elementos de natureza simbólica e relacionados à divisão sexual do trabalho, que atuam como barreiras à atuação política das mulheres.

Palavras-chaves: Partido dos Trabalhadores; Participação Política; Cotas de Gênero; Representação Política; Democracia.

\section{Women Leaders of Workers' Party: Profile and Challenges to Substantive Representation}

\begin{abstract}
This article it is a case study about the advances and limits in the political participation of women inside the Workers Party, the first party in Latin America to adopt gender quotas and to approve the parity in the composition of its directions. Data collection consisted in questionnaires to members of the National Directorate of the PT, followed by biographical research, and analysis of opinion polls conducted by Perseu Abramo Foundation (FPA). We also carried out research in the collection Sérgio Buarque de Holanda which allowed us to raise the composition of national PT directions throughout its history, and analyze the trajectory of female participation.
\end{abstract}


Finally, we work with some open interviews and in depth with women leaders of the party.

Keywords: Workers Party; Political Participation; Gender Quotas; Political Representation; Democracy.

Recebido em: 20 de maio de 2015.

Aceito para publicação em: 28 de março de 2016. 